\title{
Ophthalmic Complications of Spina Bifida and Hydrocephalus
}

\author{
H. GASTON
}

Southampton

\begin{abstract}
Summary
The article reviews the ophthalmic literature on spina bifida and hydrocephalus and presents the findings of a six-year survey of 322 children. Ophthalmic complications were found to occur very frequently. Forty-two per cent had a manifest squint, $29 \%$ lateral rectus palsy or musculoparetic nystagmus, $14 \%$ papilloedema and $17 \%$ optic atrophy. Only $27 \%$ definitely had normal visual function. Seventy per cent of proven episodes of shunt dysfunctions had positive ophthalmological evidence of raised intracranial pressure. The sudden appearance of a squint, other ocular motility disorder or papilloedema usually denotes uncontrolled hydrocephalus. Shunt surgery is the first priority but may not restore normal ocular motility and visual function. Subsequent treatment should be tailored to the special needs of these children. Regular ophthalmic supervision of these children saves life and sight.
\end{abstract}

The majority of children with spina bifida and hydrocephalus require a cerebrospinal fluid (CSF) shunt at some time in their lives. These shunts commonly become obstructed. Shunt obstruction is followed by the development of an acute or chronic rise in intracrañial pressure (ICP) which may be difficult to diagnose early as symptoms and signs are often nonspecific. A study was undertaken, therefore, to determine whether ophthalmic signs are useful evidence of raised ICP and shunt malfunction in hydrocephalic children. In addition it was hoped that regular ophthalmic supervision would help them to achieve and maintain good visual function.

The author has worked in a spina bifida/ hydrocephalus clinic for over thirteen years. Numbers attending this clinic have declined gradually due to the effect of the selective policy (whereby severely affected babies are not treated) and termination of affected pregnancies diagnosed by amniocentesis. There may also be a real decline in numbers of affected babies due to better maternal nutrition. Results are presented from a six-year period when the clinic was at its busiest. It is hoped that the author's findings will assist other ophthalmologists to serve this dwindling population of children. Though multiply handicapped, many are loved and nurtured by devoted parents and will reach adulthood. They will need good vision if they are to become independent and gain employment.

In this review article each ophthalmic complication will be dealt with separately; the literature reviews, results and discussion are recorded individually under each heading as follows:

1) Sunsetting

2) Parinaud's Syndrome

3) Squint (a) Convergent

(b) Divergent

(c) Consecutive divergence

(d) Vertical

Correspondence to: Mrs H Gaston, DM, FRCS, FCOphth, Southampton Eye Hospital, Wilton Avenue, Southampton SO9 4XW 
(e) Head posture

(f) Refractive errors

4) Lateral rectus palsy

5) Nystagmus and disorders of ocular motility

6) Papilloedema

7) Optic atrophy

8) Cortical blindness

9) Visual loss and blindness

10) Visual field defect

11) Visual function

12) Visual perception

13) Correlation of visual and general handicap

14) Uncontrolled hydrocephalus

15) Effect of selective policy

16) Deaths.

\section{Patients and Methods}

Three hundred and twenty-two children aged 0-18 years from the Wessex area who were attending Southampton General Hospital were seen over a six-year period. Their diagnoses are shown in Table I. Every effort was made to see all children with these diagnoses whether or not they had, or were likely to have, ophthalmic abnormalities. Whenever possible they were seen regularly, at each clinic visit, starting either at the time of birth or when the diagnosis was made. In addition, they were seen on an emergency basis in the clinic or on the ward, in the hope that ophthalmic examination might assist in the diagnosis of raised intracranial pressure. Anencephalics and children who did not survive the first few hours or days of life were not included in the study.

\section{(1) Sunsetting}

Sunsetting is a classic sign of hydrocephalus

Table I Diagnosis of 322 patients

\begin{tabular}{|c|c|c|}
\hline Diagnosis & No. & $\%$ \\
\hline Spina bifida occulta (SB) & 12 & 4 \\
\hline Spina bifida cystica alone (SBC) & 34 & 10.5 \\
\hline $\begin{array}{l}\text { Spina bifida with arrested hydrocephalus } \\
\text { (SBAH) }\end{array}$ & 19 & 6 \\
\hline $\begin{array}{l}\text { Spina bifida with hydrocephalus treated } \\
\text { by a shunt }(\mathrm{SBH})\end{array}$ & 141 & 44 \\
\hline Hydrocephalus alone $(\mathrm{H})$ & 108 & 33.5 \\
\hline Occipital encephalocoele (E) & 3 & 1 \\
\hline $\begin{array}{l}\text { Occipital encephalocoele and } \\
\text { hydrocephalus (EH) }\end{array}$ & 5 & 1 \\
\hline
\end{tabular}

and kernicterus, but may also occur in premature babies and transiently in normal full term babies. It may appear spontaneously or when the infant's position is changed. A child in whom sunsetting persists for more than three months will usually be found to have serious cerebral damage. ${ }^{1,2}$

The setting sun phenomenon was originally thought to be mechanical in origin due to downward displacement of the eyes by the altered direction of the orbital plates, but even in gross hydrocephalus it may be corrected by surgical relief of the hydrocephalus, ${ }^{3}$ so it is the result of a pressure effect on the brain stem in the region of the anterior end of the third ventricle. ${ }^{4}$

Results In this study, 53 patients $(16 \%)$ had a history of sunsetting. Some of the episodes were observed before the six-year period. (Table II).

\section{Discussion}

A history of sunsetting was found more frequently in this series $(16 \%)$ than in others, despite the inclusion of children with spina bifida occulta and spina bifida cystica in this series. More patients with a history of sunsetting had an underlying diagnosis of primary hydrocephalus than spina bifida with hydrocephalus, despite the fact that patients with spina bifida with hydrocephalus formed the largest diagnostic group in the series. This is probably because the development of hydrocephalus in a case of spina bifida is anticipated, and treated at an early stage. The diagnosis of primary hydrocephalus, on the other hand, may be delayed until a later stage when other clincial features such as sunsetting are obvious.

No case of persistent sunsetting was

Table II Sunsetting phenomenon

\begin{tabular}{llrr}
\hline Total patients & & 53 & $16 \%$ \\
$\begin{array}{l}\text { Number of patients with } \\
\quad \text { repeated episodes }\end{array}$ & 5 & $9 \%$ \\
Total episodes & & 58 & \\
Diagnosis & SBC & 1 & $2 \%$ \\
& SBAH & 1 & $2 \%$ \\
& SBH & 15 & $28 \%$ \\
& H & 34 & $64 \%$ \\
Subsequent optic atrophy & EH & 2 & $4 \%$ \\
& Yes & 11 & $21 \%$ \\
& No & 41 & $77 \%$ \\
\hline
\end{tabular}


observed but five patients $(9 \%)$ had repeated episodes. Sunsetting was commonest in children under six months ( $83 \%$ of episodes). This is generally in agreement with the series of Rabinowicz, who found no cases after eighteen months of age, and Goddard (only one case after six months); but $17 \%$ of episodes occurred after six months of age and one patient was seven years old when the phenomenon was observed. This accords with the cases of forced downward gaze in adults with decompensated hydrocephalus described by Cobb et al. ${ }^{8}$

Twenty-one per cent of cases with a history of sunsetting had developed optic atrophy by the end of this study. This is much less than the $50 \%$ quoted by Rabinowicz ${ }^{5}$ and is not much higher than the general incidence of optic atrophy in the series $(17 \%)$. However, an analysis of the visual handicap of those with a history of sunsetting and the series as a whole, shows a trend towards a worse visual prognosis in the former group.

\section{(2) Parinaud's Syndrome}

Parinaud's syndrome consists of paralysis of voluntary conjugate vertical eye movements with or without pupillary anomalies. It seems to represent a partial manifestation of the disorder causing the setting sun phenomenon and occurs in older patients with hydrocephalus. It may be an early reliable sign of shunt malfunction and attributable to compression of the quadrigeminal plate by a dilated suprapineal recess with compression of the aqueduct. ${ }^{7}$ A cerebrospinal fluid shunt breaks the cycle and allows the aqueduct to open.

\section{Results}

Twenty-two patients (6.5\%) showed this syndrome at some time curing the six-year study (Table III). The age at observation ranged from three weeks to 16 years. The syndrome resolved completely in eleven patients $(52 \%)$, often after shunt surgery, although in one of these it recurred on two subsequent occasions. In eight patients $(38 \%)$ the syndrome persisted in all features. In one patient the syndrome resolved partially. In the other patient there was insufficient follow-up.

\section{Discussion}

There are no figure available for comparison in the literature, although many authors have described the syndrome in non-tumoral hydrocephalus. In agreement with other reports, it was found that the syndrome was sometimes cured completely by prompt shunt surgery but persisted totally or partially in others, presumably due to irreversible changes in the brain stem. None of the children who developed this syndrome had normal visual function at the end of the study.

Like Sunsetting, the sudden appearance of Parinaud's syndrome is a useful indication of uncontrolled hydrocephalus.

\section{(3) Squint}

Squint is a very frequent feature of congenital hydrocephalus. It occurs more often in spina bifida patients with shunt treated hydrocephalus than in those without clinical hydrocephalus. ${ }^{8}$ Convergent squint is the commonest type and usually starts early in life, with a unilateral or bilateral lateral rectus palsy, ${ }^{5,6,9}$ due to an acute rise in intracranial pressure and sometimes disappears with relief of hydrocephalus. ${ }^{9,10}$ An increased angle of squint is repeatedly seen as a sign of raised intracranial pressure $^{5}$ and is sometimes the first unequivocal sign of raised pressure. ${ }^{10,11}$ After a prolonged episode of raised intracranial pressure the squint does not always revert to its previous angle. ${ }^{5}$

Though most squints are paretic in origin, concomitance develops early ${ }^{5}$ and the squint is usually alternating in character. Fully accommodative squints are uncommon ${ }^{5,6,11,12}$ as are abnormal retinal correspondence and eccentric fixation. Amblyopia is rare. , $^{5,12,13}$

An A syndrome is found in $50 \%$ of squints. It may be due to primary underaction of the

Table III Parinaud's syndrome

\begin{tabular}{|c|c|c|c|}
\hline \multirow{5}{*}{ Features } & Total patients & 21 & $6.5 \%$ \\
\hline & Upgaze nystagmus alone & 11 & $52.5 \%$ \\
\hline & Upgaze palsy & 4 & $19 \%$ \\
\hline & $\begin{array}{l}\text { Upgaze nystagmus/palsy }+ \\
\text { dilated sluggish pupils }\end{array}$ & 2 & $9.5 \%$ \\
\hline & $\begin{array}{l}\text { Upgaze nystagmus/palsy + } \\
\text { downgaze nystagmus } \\
\text { Upgaze nystagmus/palsy }+ \\
\text { downgaze nystagmus }+ \\
\text { dilated pupils }\end{array}$ & 2 & $9.5 \%$ \\
\hline \multirow[t]{2}{*}{ Diagnosis } & SBH & 17 & $81 \%$ \\
\hline & $\mathrm{H}$ & 4 & $19 \%$ \\
\hline
\end{tabular}


lateral rectus muscle $e^{5,10,14}$ or associated with downdrift in adduction due to a weakness of the inferior obliques ${ }^{9,10}$

\section{Results}

One hundred and thirty-six patients (42\%) had a manifest squint at some time during this study. This accords with figures in the literature $(30-73 \%)$ considering that the series are not strictly comparable. The present series included some cases of spina bifida occulta and spina bifida cystica who had a low incidence of squint; such cases were excluded from other series (Table IV).

The incidence of squint remains noteworthy when one considers that only $2-3 \%$ of the general population have a squint.$^{15}$ Fortyfive children $(33 \%)$ were not known to have a squint until they were seen as part of this study, so regular examination of spina bifida and hydrocephalus patients by an ophthalmologist seems fully justified.

\section{(3a) Convergent squint}

\section{Results}

This occurred in $28 \%$ of the whole series, most often in patients with shunt dependent hydrocephalus. There was evidence of lateral rectus palsy or paresis in $57 \%$ showing that this is the commonest underlying mechanism for convergent squint. An A syndrome was present in $41 \%$.

Fourteen per cent had a positive family history of convergent squint, although the true figures may be higher as many spina bifida children are fostered or adopted and know nothing of their family. Significant hypermetropia was present in $19 \%$ and fully accommodative squints were uncommon in

Table IV Incidence of squint in spina bifida and hydrocephalus

\begin{tabular}{|c|c|c|}
\hline \multicolumn{2}{|c|}{$\begin{array}{r}\text { Diagnosis of Patients } \\
\%\end{array}$} & Incidence of manifest squint \\
\hline SBO & 4 & $0 \%$ \\
\hline SBC & 10.5 & $1 \%$ \\
\hline SBAH & 6 & $3 \%$ \\
\hline SBH & 44 & $64 \%$ \\
\hline $\mathrm{H}$ & 33.5 & $32 \%$ \\
\hline E & 1 & $0 \%$ \\
\hline EH & 1 & $0 \%$ \\
\hline
\end{tabular}

this series as in others. Although major degrees of amblyopia were found to be uncommon $(1 \%)$ as in other series, minor degrees were not unusual $(36 \%)$.

Treatment of amblyopia by conventional occlusion was successfully undertaken in some cases but failed in others, perhaps because such treatment is an insupportable burden for children and their mothers who already have multiple appliances and treatment regimes to be remembered. Twenty-six children ( $29 \%$ of convergent squints) had had squint surgery with beneficial results. This must be balanced against the 14 children with divergent squints following convergent squint surgery. In addition two children with the A syndrome were divergent in downgaze after surgery for a convergent squint, despite being straight or only minimally convergent in the primary position.

\section{Discussion}

Convergent squint was found less often in this series $(28 \%)$ than that of Rabinowicz 5 (44\%) and Clements and Kaushal $^{9}(67 \%)$; the inclusion of patients with spina bifida occulta and older patients (who were more likely to have consecutive divergence) in the trial may account for this. The A syndrome occurred much more often than is usual in squints. (Stanworth ${ }^{16}$ estimates that the A syndrome occurs in $1 / 10$ th to $1 / 15$ th of all squints) and adds support to the theory that lateral rectus palsy is the usual cause of convergent squint in these cases.

\section{(3b) Divergent squint}

\section{Results}

Twenty-seven patients ( $8 \%$ ) had a manifest divergent squint without a history of preceding convergent squint. However, nine of these $(33 \%)$ had signs of lateral rectus palsy or paresis and five (18.5\%) had an A syndrome, suggesting that some of these squints were in fact cases of consecutive divergence. Eight $(30 \%)$ had a major visual handicap. Significant myopia was only present in two patients $(7 \%)$. More patients with divergent squints had primary hydrocephalus or encephalocele with hydrocephalus than would have been expected from their incidence in the series as a 
whole. This may be because divergent squint was frequently associated with a major visual handicap which was commoner in primary hydrocephalus and encephalocele with hydrocephalus than in spina bifida with hydrocephalus.

\section{(3c) Consecutive divergence}

\section{Results}

Twenty patients ( $6 \%$ of the series) had a consecutively divergent squint. This followed convergent squint surgery in $14(70 \%)$ but occurred spontaneously in six $(30 \%)$. Lateral rectus palsy $(75 \%)$ and the $\mathrm{A}$ syndrome $(35 \%)$ were at least as common in this group as in those with convergent squints $(57 \%$ and $41 \%)$.

\section{Discussion}

It is interesting to note that weakness of abduction does not protect against the development of consecutive divergence and it is important to realise that a high proportion of convergent squint operations in these children will be followed by this complication. There must, therefore, be a considerable predisposition in these children for the eyes to diverge. Recognition of convergence weakness might help to forewarn surgeons of the likelihood of consecutive divergence. Spontaneous divergence was most often seen at about the age of ten years. Frequently there was a period of time during which the squint was only divergent in depression and straight or convergent in the primary position and elevation, before the squint became divergent in the primary position or all positions of gaze.

\section{(3d) Vertical squint}

Thirty-eight patients $(11 \%)$ had a vertical component to their squint (Goddard ${ }^{6}$ gives an incidence of $30 \%$ ).

\section{(3e) Head posture}

A marked chin up position due to the A syndrome with convergent squint was found in four children. A noticeable chin down posture due to divergent squint with A syndrome was found in one child.

The disabling effect of a compensatory head posture in children already handicapped by poor mobility and spinal deformities should highlight the need for this syndrome to be treated at the same time as convergent or divergent squint surgery.

A head turn in lateral rectus palsy was seen in seven cases but field defects, nystagmus and discomfort in the neck due to shunt procedures may have contributed to the abnormal head posture.

\section{(3f) Refractive errors}

These were found in 71 children $(22 \%)$. This finding compares closely with the 16-25\% incidence in other series. ${ }^{8,17,13}$ Most squints in these children appear to be based on lateral rectus palsy rather than hypermetropia. However a refraction should be carried out whenever there is either poor visual acuity or a squint because of the help it may give in individual cases. A poor school performance by these children may be falsely ascribed to mental deficiency when an easily remediable condition such as myopia exists. However, spectacles should not be prescribed unless the children are clearly likely to benefit for they are already burdened with so many other appliances.

In a few of these children myopia may have been the only sign of the retinopathy of prematurity. Many of the primary hydrocephalics had been born prematurely and a few had other signs of retinopathy.

\section{(4) Lateral Rectus Palsy/Paresis/Musculo- paretic Nystagmus}

\section{Results}

This was diagnosed in 93 cases $(29 \%)$ at some time. Only three cases of lateral rectus palsy with associated convergent squint completely resolved without residual paretic nystagmus (nystagmus on abduction) or residual squint. They were aged three, four and ten years and had all had evidence of at least low grade binocular single vision (i.e. Wirt Fly positive) before this episode. The resolution took place after shunt surgery and without squint surgery. In other cases full abduction usually returned as time went on and the squint became concomitant, but nystagmus on abduction persisted. Only one patient had a permanent complete palsy, i.e. inability to abduct one eye. 


\section{Discussion}

There are no figures for comparison in the available literature, although it is generally agreed that such a palsy is very common and is the underlying cause of the majority of squints and of nystagmus $(28 \%) .{ }^{8}$ Lateral rectus palsy was found in one case classified as having spina bifida cystica alone, suggesting that this child had had significant hydrocephalus at some time.

\section{(5) Nystagmus and disorders of ocular} motility

The following types of nystagmus were observed in this series-pendular, jerk, micronystagmus and musculo-paretic nystagmus. Ten children $(3 \%)$ had horizontal pendular nystagmus - a similar figure to that of Rabinowicz 5 (4\%); all children so affected had poor vision when they were old enough for it to be tested. The underlying diagnosis was primary hydrocephalus in $90 \%$ and spina bifida with hydrocephalus in $10 \%$. (In the series as a whole primary hydrocephalus formed $33.5 \%$ and spina bifida with hydrocephalus $44 \%$ ). This was due, presumably, to the more frequent occurrence of major visual handicap in primary hydrocephalus than in spina bifida with hydrocephalus.

Some other ocular motility disorders were observed which have not been reported in other series. These included internuclear ophthalmoplegia, conjugate lateral gaze palsy, and horizontal jerk nystagmus of second and third degree. The latter two disorders were seen only in severely ill patients, several of whom subsequently died. Conjugate lateral gaze palsy was seen mainly in children with primary hydrocephalus and in those with a major visual handicap.

\section{(6) Papilloedema}

Most authors have found papilloedema to be a rare event in congenital hydrocephalus. The great variety of reasons given for this is not surprising since the precise pathogenesis of papilloedema is still a controversial subject. ${ }^{18}$ Hayreh $^{19}$ stated that papilloedema occurs only when the subarachnoid cerebro-spinal fluid pressure is raised and not in obstructive hydrocephalus with distended ventricles. Goddard $^{6}$ attributed the rarity of papilloe- dema in congenital hydrocephalus to the ease with which the infant's skull expands; this would indicate that the generalised intracranial pressure is congenital hydrocephalus is seldom raised. Nevertheless, the intracranial pressure must by definition be raised at some time in hydrocephalus, whether it is communicating or obstructive, and indeed continuous intraventricular pressure monitoring may be used to diagnose uncontrolled hydrocephalus. ${ }^{20,21}$ Perhaps, however, the intracranial pressure is never enough to cause papilloedema while the skull remains expansile.

Early insertion of a shunt is now often followed by premature skull fusion, so that the skull soon becomes non-expansile. Then shunt obstruction may be followed by an abrupt rise in intracranial pressure.$^{6,5,11}$ Papilloedema may be due to raised pressure in the infratentorial compartment of the skull, even when the lateral ventricles are successfully drained by a shunt; thus a CT scan showing small ventricles may be misleading. Papilloedema may be superimposed on optic atrophy if arrested hydrocephalus decompensates. ${ }^{5}$ The atrophic nerve head is probably more resistant to oedematous changes so that papilloedema supervening on an atrophic disc usually reflects markedly raised intracranial pressure. ${ }^{22}$ Papilloedema can be, but need not be, the prelude to serious visual decline. ${ }^{5}$

\section{Results}

In this study, papilloedema was observed in 44 children $(14 \%)$ of the total series at some time (Table V). It was recurrent in two cases so 46 episodes were observed, 43 of them during the six-year period.

\section{Discussion}

This incidence is far higher than that quoted by Goddard Gless than 1\%), Rabinowicz $^{5}$ $(2 \%)$, Harcourt ${ }^{11}(3 \%)$, although Ghose ${ }^{22}$ more recently found an incidence of $14.5 \%$. It must be emphasised that the $14 \%$ incidence in this study is based on examinations performed (sometimes repeatedly) over a long period and that a figure derived from single examinations within a short period of time would necessarily be much lower.

At least one child in the series still had an open anterior fontanelle at the time papilloe- 
Table V Papilloedema

\begin{tabular}{llrr}
\hline & & No & $\%$ \\
\hline Total patients & & 44 & 14 \\
Unilateral & & 4 & 9 \\
Bilateral & & 40 & 91 \\
Age & SBH & 34 & years \\
Diagnoses & H & 9 & 77 \\
& EH & 1 & 20 \\
\hline
\end{tabular}

dema was noted so it cannot be assumed that the expansibility of the infant's skull provides complete protection against the development of papilloedema. Sixteen per cent of children with a history of papilloedema died within the six-year period which emphasises the seriousness of this condition; $5 \%$ of the total series died. In addition at least $14 \%$ subsequently developed optic atrophy. However, a few children recovered with no visual or general handicap, thus the prognosis need not be gloomy if treatment is prompt.

Although uncommon, papilloedema was of the greatest possible help in the pre-operative diagnosis of raised intracranial pressure which otherwise may have had to be made on the basis of non-specific signs. Indeed, in one case the patient was without either symptoms or signs, papilloedema being discovered on routine examination. Papilloedema was sometimes present when the valve was pumping normally. In this study papilloedema was taken as an absolute indication for shunt surgery.

The significance of papilloedema was not always appreciated by junior paediatricians even when the fundi had been inspected. Indeed, at the start of the study it was rare to find any mention of fundus examination in the case notes, even when the child had been admitted as an emergency with symptoms of raised intracranial pressure. However, by the end of the study ophthalmic opinion was much more often sought and sometimes used as the criteria for surgery or discharge from Hospital.

Papilloedema usually took several weeks to resolve after an episode of raised intracranial pressure even when shunt surgery was judged to be successful on other evidence. In four, it was still persistent after three months; in one of these it was still present to some extent after ten months. Three of the four cases were entirely symptom-free and had no further shunt surgery during the period when papilloedema persisted. One of the four was admitted three months after surgery (for papilloedema) with suspected valve disfunction, but had no further operation. The diagnosis of raised intracranial pressure was thus more difficult during this period, but repeated careful examination of the discs was still helpful so that the clearing of haemorrhages and the lessening of the oedema could be sought. Papilloedema was recurrent on two occasions, therefore a history of papilloedema may be helpful in denoting children who are potentially likely to suffer this diagnostic complication during future episodes of raised intracranial pressure. However, the absence of papilloedema provided no reassurance about intracranial pressure.

\section{(7) Optic atrophy}

Optic atrophy is generally agreed to be common in spina bifida and hydrocephalus. ${ }^{5} \mathrm{An}$ assessment of the true incidence is difficult because the optic disc is always pale in infants. ${ }^{6}$ The vision may vary from $6 / 9$ or better $(28 \%)$ to perception of light. Sixty per cent of children with atrophic discs have a vision of $6 / 12$ or worse. ${ }^{5}$ Though optic atrophy may coexist with good vision, these children are particularly vulnerable as a number of those with severe visual deterioration have shown marked optic atrophy with good vision at an earlier stage.

Optic atrophy is most often attributed to stretching of the optic nerves or their vascular supply. ${ }^{6,11,4}$ This occurs when the brain stem shifts in position. A sudden drop in intracranial pressure, following a shunt operation, may cause just such a change in position. Optic atrophy may also be due to an associated developmental anomaly. It may be secondary to raised intracranial pressure or meningitis. ${ }^{23,6}$ Optic atrophy is one of the main causes of blindness in hydrocephalus, ${ }^{12}$ although cortical blindness may coexist. $^{24,23,11,5}$

\section{Results}

Fifty-five children (17\%) had optic atrophy at 
the time this study ended (Table VI). Optic atrophy sometimes appeared after an episode of papilloedema. Nevertheless, it was found that the optic discs often looked pale during and after the period of resolution of papilloedema so that atrophy should not be diagnosed ill-advisedly. As in other studies there were a few (3) cases in which papilloedema was: superimposed on optic atrophy; the presence of pale discs provides no excuse for failure to examine the fundi in future. Notably, these three cases with papilloedema on atrophy all died before the end of the study. Therefore the finding is one of the utmost gravity.

\section{Discussion}

Optic atrophy was quite common $(17 \%)$ in this series. Rabinowicz ${ }^{5}$ found a higher incidence of $31 \%$. The incidence of atrophy in this study would have been higher if cases of transient pallor after an episode of papilloedema had been included.

No child with optic atrophy had normal visual function, although $31 \%$ had only minor defects (Rabinowicz 5 found $28 \%$ had a vision of $6 / 9$ or better). Sixteen per cent definitely had a major visual handicap, i.e. were eligible for blind or partially sighted registration, and some of the children who were too young for visual acuity to be tested will probably fall into this category eventually.

There was a history of papilloedema in six of the 55 cases but it may have occurred unrecognised in many more. Gross cupping of the atrophic optic disc was found in ten cases $(18 \%)$; this suggests a preceding pathological lesion occurring at the optic disc itself e.g. papilloedema rather than in the retrobulbar optic nerve, optic tract or lateral geniculate body.

A history of prematurity, meningitis, septicaemia, multiple shunt operations or delayed

Table VI Optic atrophy

\begin{tabular}{llcc}
\hline & & No & $\%$ \\
\hline Total & & 55 & 17 \\
Bilateral & 39 & 71 \\
Unilateral & & 16 & 29 \\
Disc cupping & & 10 & 18 \\
Diagnoses & SBH & 25 & 45 \\
& H & 29 & 53 \\
& EH & 1 & 2 \\
\hline
\end{tabular}

surgical intervention were also common in cases of optic atrophy. Optic atrophy without papilloedema was sometimes associated with chronically raised intraocular pressure. It is never safe to diagnose primary optic atrophy. Shunt function should always be investigated if the pathogenesis of the optic atrophy is unknown. Optic atrophy was seen more often in primary hydrocephalus than in cases of spina bifida with hydrocephalus, although the former formed a smaller proportion of the series as a whole. This may reflect the fact that primary hydrocephalus is often diagnosed at a later stage and that primary hydrocephalics were more likely to have been born prematurely and have had a stormy neo-natal period.

Optic atrophy was also found more often in those with severe general handicaps and the death rate of affected children was $18 \%$ compared with $5 \%$ in the series as a whole. Children with optic atrophy are therefore a visually and generally handicapped group, predisposed to further visual and general deterioration and death.

\section{(8) Cortical blindness}

Cortical blindness is probably the result of oedema and swelling of the brain secondary to hypoxia, septicaemia, meningitis, multiple operations, trauma and convulsions. Both posterior cerebral arteries are occluded on the tentorial edge. ${ }^{4,24}$ It may develop very suddenly. It may coexist with optic atrophy. The diagnosis is only established with certainty by an absent visual evoked response. Blindness may occur acutely or insidiously, due to shunt malfunction or to operations on the shunt.

\section{Results}

Nine patients $(3 \%)$ had cortical blindness. Eight also had a degree of optic atrophy. They all had primary hydrocephalus or encephalocoele with hydrocephalus. Multiple severe medical problems in the neo-natal period and delay in diagnosis and treatment may account for the occurrence of cortical blindness in this group but not in spina bifida with hydrocephalus. Two children with cortical blindness had died by the time the study ended and none of the survivors were without some general handicap. 
(9) Visual loss and blindness

Optic atrophy and cortical blindness are sometimes not differentiated as a cause of visual loss and blindness in the literature, e.g. Rabinowicz ${ }^{5}$, Lorber, ${ }^{23}$ Keen ${ }^{25}$ and Welch ${ }^{26}$ all describe acute or insidious loss of vision (sometimes reversible) in hydrocephalus, usually secondary to shunt obstruction.

\section{Results}

In this study three patients ( $1 \%)$ had a sudden decline in visual acuity at a time when shunt blockage was suspected for other reasons. One had papilloedema. In only one case was the visual decline dramatic, VA $6 / 9,6 / 6$ to counting fingers both eyes. In each case the visual loss was taken as an indication for urgent shunt surgery and the vision rapidly recovered afterwards, at any rate for a while. Other cases had a history of transient visual obscurations without measurable decline in visual acuity.

\section{Discussion}

No case of measurable permanent decline in the children under regular observation occurred during the study and this must surely reflect the increased attention paid to ophthalmic signs and symptoms and the greater willingness to operate for shunt disfunction on the basis of disordered visual function which gradually developed as the research progressed. Nevertheless, the literature and the history of events occurring before the six-year study demonstrate the vulnerability of the optic nerve to raised intracranial pressure.

Neglect of a blocked shunt may result, not in a dead child, but in a permanently blind one.

\section{(10) Visual Field Defect}

\section{Results}

Fifteen children $(5 \%)$ in the series had field defects demonstrable on confrontation testing. Five had generalised restriction (very gross in one); they all had spina bifida and hydrocephalus. Two had inferior altitudinal defects in both eyes (one had spina bifida, the other had hydrocephalus). Two had quadrantanopias (one with SBAH, on with SBH), six had homonymous hemianopias.

\section{Discussion}

Rabinowicz ${ }^{5}$ found $9 \%$ to have field defects and the types of defects in both series were similar. A much higher incidence of defects may have been found if all the patients had been old enough for detailed testing.

\section{(11) Visual Function}

\section{Results}

Only $86(27 \%)$ children in this study had normal visual function (Table VII).

\section{Discussion}

This compares fairly well with Rabinowicz, ${ }^{5}$ finding of $37 \%$ with a vision of $6 / 6$ or better, bearing in mind that he did not have an unclassified group and that all his cases had spina bifida with hydrocephalus or primary hydrocephalus. Similarly $34 \%$ of Hunt's ${ }^{13}$ group of school children were without visual defects. However, $13 \%$ of the 'normal' group had had transient eye problems (squint, lateral rectus palsy, papilloedema) not permanently reducing visual function so that few children escaped without some effects on their eyes. Also, many of this 'normal' group had spina bifida occulta or spina bifida cystica-conditions which should not be associated with eye complications.

Twenty-three per cent of the children had a 'minor' visual handicap. Squint, amblyopia and minor degrees of optic atrophy, with their adverse effect on visual acuity, binocular vision and field were the underlying mechanisms.

Table VII Summary of visual function

\begin{tabular}{llcc}
\hline & No & $\%$ \\
\hline $\begin{array}{l}\text { Total } \\
\text { Normal }\end{array}$ & $\begin{array}{l}\text { VA 6/6 or better both } \\
\text { eyes full fields and } \\
\text { stereopsis. }\end{array}$ & 100 \\
Minor & $\begin{array}{l}\text { VA 6/9_6/12 one eye or } \\
\text { manifest squint, or } \\
\text { absent BSV or minor } \\
\text { field defect }\end{array}$ & 76 & 27 \\
Moderate & $\begin{array}{l}\text { VA 6/18_6/36 or major } \\
\text { field loss in one eye }\end{array}$ & 18 & 5.5 \\
Major & $\begin{array}{l}\text { VA 6/18-6/36 or major } \\
\text { field loss in onie eye. PS } \\
\text { or Blind } \\
\text { Too young or retarded to }\end{array}$ & 11 & 3 \\
test or incomplete & 13 & 4 \\
\hline
\end{tabular}


Five and a half per cent of children had a moderate visual handicap. Amblyopia due to squint was the commonest cause of unilateral visual defect; optic atrophy, macular scarring and amblyopia due to ptosis were the remaining mechanisms. In contrast, Rabinowicz ${ }^{5}$ attributed most of his $6 / 18$ or worse in one eye group to underlying optic atrophy and found amblyopia to be rare.

Eleven children (i.e. $3 \%$ ) in this study had a major visual handicap. Rabinowicz ${ }^{5}$ found $7 \%$ eligible for blind registration, (he did not have an unclassified group) and Hunt $^{13}$ found $2 \%$ of her group of school age children to be educationally blind. Major visual handicap was invariably associated with severe or very severe general handicap and $18 \%$ of the group died during the study period. An analysis of the case histories of these eleven children suggests that some of the visual handicap could have been avoided in at least nine cases. Delayed surgical intervention was undoubtedly responsible for the development of optic atrophy in the two children with spina bifida and hydrocephalus. Retinopathy of prematurity was responsible in two cases so that better control of arterial oxygen in the special care nursery migh have helped these cases. A third child with optic atrophy and nystagmus had been born prematurely. Again better treatment of infected shunts or neonatal meningitis might have salvaged four other cases.

Many children in this study (41\%) fell into the unclassified group becuse their youth prevented testing of Snellen visual acuity or because they were lost to follow-up before ophthalmic examination could be completed.

Thus, only a small proportion of children with hydrocephalus, who are old enough to be tested, escape without some visual disturbance and routine ophthalmic assessment is therefore justified.

\section{(12) Visual Perception}

Although not tested in this study, many children gave a history of visual-perceptual problems noted at school by teachers or educational psychologists, as would be expected from the literature. Since some of these were children with 'normal' visual function as assessed on the basis of acuity, stereopsis and field, the number of children with hydrocephalus who escape without any damage to their vision or visual perception must be small indeed.

\section{(13) Correlation of Visual and General \\ Handicap}

Only $12 \%$ of the children in the study had no general handicap. In $15.5 \%$ the handicap was mild, $23 \%$ intermediate, $21 \%$ severe, $15 \%$ very severe and $14 \%$ were too young to be classified. Thus more children proved to have general handicaps than visual handicaps (although more children could be classified generally than visually). Those with the severest general handicaps tended to have the severest visual handicaps too, although two children with very severe general handicaps had normal visual function and 13 children only a minor visual defect. A major visual handicap only occurred in those already crippled with severe or very severe general handicaps.

\section{(14) Uncontrolled Hydrocephalus}

The aim of this part of the study was to determine the percentage of children with uncontrolled hydrocephalus who have ophthalmic evidence of raised intracranial pressure and to correlate the ophthalmic and general findings with the nature and duration of the obstruction and the height of the CSF pressure. Cases were analysed if the following criteria were fulfilled;

(i) An eye examination had been performed during a period of suspected raised intracranial pressure due to uncontrolled hydrocephalus.

(ii) At operation they were found to have a shunt obstruction requiring revision or to have raised intracranial pressure requiring the insertion of a shunt for the first time.

Cases were selected for the study merely on the basis of their availability for study of their eyes before operation. Many patients with acute symptoms came to surgery before such examination could be performed and could not be included in the analysis. Findings were classified as (a) positive-there was ophthalmic evidence of raised intracranial pressure or (b) negative-no such ophthalmic evidence.

\section{Results}

Fifty-three episodes of raised intracranial 
pressure fulfilled the criteria for this part of the study.

In $70 \%$ of those episodes there was positive ophthalmological evidence of raised intracranial pressure and only $30 \%$ had negative eye findings. Since these episodes tended to be the less acute ones in which there was time for more investigation before surgery (and sometimes doubt about the necessity for surgery) this is a finding of considerable practical importance. In $17 \%$ of cases the shunt appeared to be pumping normally, although at surgery it was obviously blocked, and in $6 \%$ there were no signs and symptoms apart from those relating to the eyes.

In $51 \%$ the positive eye finding was that of papilloedema. In the remainder sunsetting, blurred vision, or a new/increased Parinaud'ssyndrome, convergent squint, or lateral rectus palsy/paresis were the criteria for diagnosing raised intracranial pressure. In the most dramatic case a divergent squint became convergent.

\section{Discussion}

There seems to have been no similar investigations of proven cases of uncontrolled hydrocephalus in the literature. The high incidence of positive ophthalmic findings does support the view that an ophthalmologist has a vital role to play in the spina bifida clinic. Eye signs were present more often in those with distal catheter blockage, perhaps because this tends to cause a slower rise in pressure than proximal catheter blockage, giving time for slowly progressive lesions such as papilloedema to develop. However, all types of shunt dysfunction were associated with eye signs.

It was not apparent from the available data why papilloedema occurred in some cases of raised intracranial pressure and not others.

In one child raised intracranial pressure had been suspected for six months on the basis of a new lateral rectus paresis, and for two months on the basis of the appearance of Parinaud's syndrome before papilloedema finally developed and shunt surgery was expedited. Thus papilloedema may develop only when raised ntracranial pressure has attained a high level. Because of the risk of consecutive optic atrophy, raised intracranial pressure should, if possible, be diagnosed before papilloedema develops. Again, this probably requires an ophthalmologist, familiar with the child who can detect early change in ocular motility.

(15) Effect of the Selective Policy

Despite the introduction of selection during 1971-73, children with minor, moderate and major visual handicaps continue to be found. Further comparison of pre and post selection figures would probably be invalid since at present a very large proportion $(34 \%)$ of those in the post-selective era are unclassifiable, whereas only $4 \%$ of those in the preselective era cannot be tested. Moreover it must be remembered that spina bifida and hydrocephalus are progressive diseases so that children in the pre-selective group (being older) are more likely to have acquired visual handicaps with time, than the younger postselective group.

\section{(16) Deaths}

There were 15 deaths during the study period $(5 \%)$. Apart from one child with spina bifida occulta who had an unassociated muscle disorder, they all had hydrocephalus (with spina bifida, primary or with encephalocoele). They were in the groups with more severe general and visual handicaps. No child with normal visual function died. More of the children who died came from the post-selective group, presumably because death in these children is commonest in their early years, and all children in the pre-selective era were at least seven years old when the study commenced.

\section{Conclusion}

This study has shown the high incidence of ophthalmic complications in children with spina bifida and hydrocephalus. It presents evidence that an interested ophthalmologist may assist in the diagnosis of uncontrolled hydrocephalus, thus minimising damage to visual function and to life itself.

I should like to thank Mr J D Atwell and Professor A R Elkington for drawing my attention to the need for this study and the Paediatric Surgeons and Ophthalmologists in Wessex for allowing me to study their patients. I am also very grateful to Mrs Sheila Davies for secretarial help.

\section{References}

${ }^{1}$ Willi von H: Das reflex artige Auftreten des soga- 
nannten Phanomens der untergehenden Sonne bei Fruh-gerburten und cerebral geschadigten Neugeborenen. Ann Paediatr (Basel) 1950, 174: 87-96.

${ }^{2}$ Stillhart H: Uber die Klinische Bedeutung des sogenannten relexartigen Phanomens der untergehenden Sonne beim Neugehenden Sonne Beim Neugeborenen. Helv Paediatr Acta 1954, 9: 298-331.

${ }^{3}$ Swash M: Disorders of ocular movement in hydrocephalus. Proc Roy Soc Med 1976, 69: 480-4.

${ }^{4}$ Wybar K: Disorders of ocular motility in hydrocephalus in early childhood. Trans II Congr Int Strabis Ass 1974, 366-70.

${ }^{5}$ Rabinowicz IM: Visual function in children with hydrocephalus. Trans Ophthalmol Soc UK 1974, 94: 353-66.

${ }^{6}$ Goddard UK: Ocular changes in hydrocephalus. $\mathrm{Br}$ Orthopt J 1965, 22: 72-80.

${ }^{7}$ Shallat RF, Pawl RP, Jerva MJ: Significance of upward gaze palsy. (Parinaud's syndrome) in hydrocephalus due to shunt malfunction. $\mathrm{J} \mathrm{Neu}$ rosurg 1978, 38: 717-21.

${ }^{8}$ Cobbs WH, Schatz NJ, Savina PJ: Midbrain eye signs in hydrocephalus. Trans Am Neurol Assoc 1978, 103: 130.

${ }^{9}$ Clements DB and Kaushal K: A study of the ocular complications of hydrocephalus and menimgomyelocoele. Trans Ophthalmol Soc UK 1970, 90: 383-90.

${ }^{10}$ Wybar K and Walker J: Surgical management of strabismus in hydrocephalus. Trans Ophthalmol Soc UK 1980, 100: 475-78.

${ }^{11}$ Harcourt RB: Strabismus affecting children with multiple handicaps. Br J Ophthalmol 1974, 58: 272-80.

${ }^{12}$ Jones $\mathrm{H}$ and Long $\mathrm{C}$ : Visual handicap in children with spina bifida-The role of the Royal National Institute for the Blind Advisory Service. Child
Care Health Dev 1976, 2: 91-7.

${ }^{13}$ Hunt GM: Spina bifida. Implications for 100 children at school. Devel Med Child Neurol 1981, 23: 160-72.

${ }^{14}$ Urist MJ: The aetiology of the so-called A and V syndromes. Am J Ophthalmol 1958, 46: 835-44.

${ }^{15}$ Black PD: Ocular defects in children with cerebral palsy. Br Med J 1980, 3: 487-8.

${ }^{16}$ Stanworth A: The A and V phenomena. Br Orthopt $J$ 1968, 25: 12-281.

${ }^{17}$ Tew BJ and Laurence KM: Ocular defect, intellectual and motor performance in children with spina bifida cystica. Z Kinderchir 1978, 25: 324-30.

${ }^{18}$ Howell DA: Clinical and pathological consequences of lumps and swellings inside the cranium. $\mathrm{Br} J$ Hosp Med 1979, 21: 60-6.

${ }^{19}$ Hayreh SS: Pathogenesis of optic disc oedema in raised intra-cranial pressure. Trans Ophthalmol Soc UK 1977, 96: 404-7.

${ }^{20}$ Simpson D: Living with hydrocephalus. $\mathrm{Br}$ Med J 1984, 288: 813-4.

${ }^{21}$ Hemmer R and Bohm B: Once a shunt. Always a shunt. Devel Med Child Neurol 1976, 18 (Suppl 37): 69-73.

${ }^{22}$ Ghose S: Optic nerve changes in hydrocephalus. Trans Ophthalmol Soc UK 1983, 103: 217-20.

${ }^{23}$ Lorber J: Recovery of vision following blindness in children with hydrocephalus or following pyogenic meningitis. Clin Paediatr (Phila) 1967, 6: 699-703.

${ }^{24}$ Lawton Smith J, Walsh TJ, Shipley T: Cortical blindness in congenital hydrocephalus. Am J Ophthalmol 1966, 62: 251-7.

${ }^{25}$ Keen JH: Blindness in children with myelomeningocele and hydrocephalus. Devel Med Child Neurol 1973, 15 (Suppl 29): 112.

${ }^{26}$ Welch K: Selected topics relating to hydrocephalus. Exp Eye Res 1977, 25 (Suppl): 345-75. 